\title{
FRESHNESS GRADING OF SHELL EGGS USING A DIELECTRIC TECHNIQUE AND ARTIFICIAL NEURAL NETWORK METHOD
}

\author{
Angelo Fabbri, Luigi Ragni, Annachiara Berardinelli, Chiara Cevoli, Alessandro Giunchi, Adriano Guarnieri
}

\section{Introduction}

According to the European Commission Regulation [10], packing centres shall grade eggs in freshness categories on the basis of the height of the air cell, that increases during storage [23]. In particular, for shell eggs, the air cell height must not exceed $6 \mathrm{~mm}$, for grade A eggs, and $4 \mathrm{~mm}$ for grade A "extra" eggs. The increase in size of the air cell is related to the evaporation of the egg content moisture through the shell pores and consequently to the aging process [27]. The dynamic of evaporation is mainly due to the storage conditions such as the temperature and the humidity [29].

In industrial environment the air cell height measurement is carried out by means of an on-line candling equipment combined to the operator visual inspection; the method uses a bright light source placed behind the egg. However, during grading, the air cell space is difficult to assess because of the high speed of the working process (about 120000 eggs per hour); moreover, during the first days after laying, the candling does not seem able to be significantly effective [5].

Recently, several non-destructive methods were proposed to determine egg freshness based on visibleNIR spectroscopy [3, 13], electronic nose system [9] and the analysis of the dielectric properties [2, 22]. Dielectric characteristics of the material vary with moisture content, density, composition, structure and water activity [20]. Using a multiple linear regression

\footnotetext{
Paper received 24.11.2007; accepted 20.10.2008
}

Eng. Angelo Fabbri PhD, aggregate professor; dr. Luigi Ragni $\mathrm{PhD}$, aggregate professor; dr. Annachiara Berardinelli $\mathrm{PhD}$, post doctoral research fellow; dr. Chiara Cevoli, PhD student; dr. Alessandro Giunchi $\mathrm{PhD}$, post doctoral research fellow; prof. Adriano Guarnieri, full professor; Agricultural Economics and Engineering Department, University of Bologna, Piazza G. Goidanich, 60 - 47023 Cesena (FC), Italy.

Eng. Fabbri: statistical data analysis. Dr. Ragni: dielectric measurement tool design and building. Dr. Berardinelli: laboratory measurement and data analysis. Dr. Cevoli: lab measurement. Dr. Giunchi: assistance in lab measurement. Prof. Guarnieri: general research management. analysis, Ragni et al. [22], showed $\mathrm{R}^{2}$ values up to 0.797 for the prediction of the air cell height from dielectric parameters. These results have encouraged further studies in order to assess the freshness parameters of shell eggs, in combination with artificial neural network (ANN) methods.

The present work refers about possibility of nondestructively grading shell eggs in the freshness categories A "extra" and A, by means of the simple technique set up by Ragni et al. [22], and the multi-layer ANN method. The performance of the ANN method will be compared with the linear discriminant function analysis and the hierarchical tree cluster analysis.

\section{Artificial Neural Networks (ANN)}

ANN is a mathematical algorithm which has the capability of relating two groups of variables, learning from examples through iteration, without requiring a prior knowledge on the relationship model [26]. Neural networks are effective for modelling, optimization, and process control of complex problems [11]. Studies have been reported for the classification of several agricultural products, such as fruits [8, 16, 19, 30], fish and meat $[6,27]$, and vegetables $[4,21]$.

The ANN is made up of a group of interconnected artificial neurons or nodes. Each node transforms an input, by means a weighted sum and a specific transfer function, and sends its output to other nodes to which it is connected. The network is trained with a subset of observations and is validated checking its ability to predict a set of known output [14].

The multi-layer perceptron (MLP) is the most popular type of neural network used today. MLP consists of a number of simple nodes or processing elements (PE) arranged in layers. The inputs to each processing element are actually fully connected to the outputs of the previous layer. A learning algorithm modifies the weights associated with each PE such that the system minimises the error between the target output and the network's calculated output. The most common supervised learning algorithm used is the back-propagation of errors. In back propagation, the gradient vector 
of the error surface is calculated. This vector points in the direction of steepest descent from the current point, so we know that if we move along it a short distance, we will decrease the error. A sequence of such moves (slowing as we near the bottom) will eventually find a minimum of some sort. The learning rate is a control parameter of some training algorithms, which controls the step size when weights are iteratively adjusted. The algorithm is also usually modified by inclusion of a momentum term: this encourages movement in a fixed direction, so that if several steps are taken in the same direction, the algorithm picks up speed, which gives it the ability to escape local minima, and also to move rapidly over flat spots and plateaus.

The algorithm therefore progresses iteratively, through a number of epochs.

The number of nodes in the system, should be directly related to the complexity of the system being modelled. Although many layered architecture can be applied, it has been shown that one hidden layer is usually sufficient to solve many problems [12].

It has been recognised that the network predictability and performance should be optimised with respect to the size of the training data set, number of hidden layers, numbers of neurons in the hidden layer, type of learning rule and the transfer function [1].

\section{Materials and methods}

\subsection{Samples}

Experiment was conducted on 6 samples of 30 eggs (from Brown Hy-Line hens, 50 weeks old), after $1,4,7,10,13$ and 16 days of storage at $20^{\circ} \mathrm{C}$, respectively. From laying to 16 days of storage at $20^{\circ} \mathrm{C}$, the height of the air cell increases almost linearly from about $1 \mathrm{~mm}$ to about $5.5 \mathrm{~mm}$ [24]; this storage generates a well balanced dataset of eggs with A "extra" and A characteristics.

\subsection{Dielectric parameters}

Figure 1 shows the instrument layout [22] used to acquire dielectric parameters. The sine wave RF oscillator is characterized by a parallel inductance and capacitance circuit driven by a single high speed switching transistor powered by a $4 \mathrm{~V}$ power supply. Two parallel rectangular plane plates made of laminate epoxy glass (1.6 mm of thickness) covered by $35 \mu \mathrm{m}$ thin copper film, form the capacitor probe. A digital oscilloscope (150 MHz of maximum bandwidth, Goodwill-Instek, GDC $820 \mathrm{C}$ ) is connected to the oscillator output in order to measure the frequency and the peak to peak voltage of the sine wave.

Measurements were carried out without and with the egg in the capacitor probe in two positions $a$ e $b$; the second position was obtained rotating the egg of $90^{\circ}$ from its initial position around its vertical axis.
The following parameters were measured: AF ( $\mathrm{MHz}$, average value of the frequencies measured in $a$ and $b$ ); AV (V, average of the peak to peak values in $a$ and b); $\Delta \mathrm{F}$ (megahertz, difference between the frequency measured without the egg in the probe and the average value $\mathrm{AF}) ; \Delta \mathrm{V}$ ( $\mathrm{V}$, difference between peak to peak value measured without the egg in the probe and the average value $\mathrm{AV}$ ).

The frequency of oscillation of the system without the egg during the measurements was 120.950 $\pm 0.075 \mathrm{MHz}$ depending on the ambient characteristics such as temperature and humidity of the air.

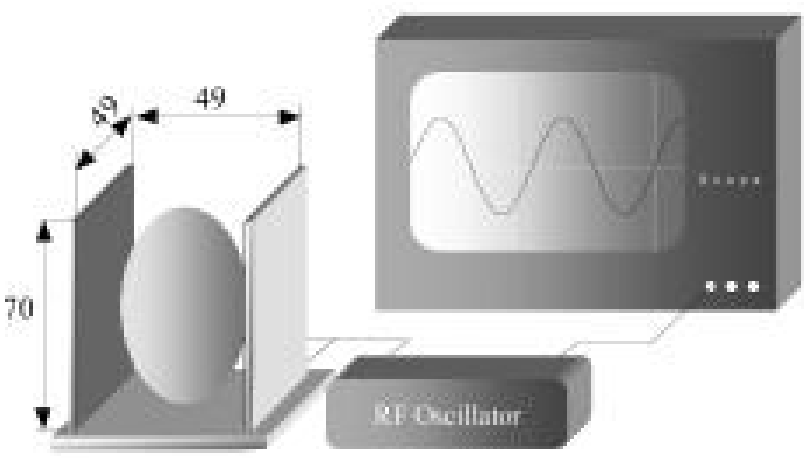

Fig. 1 - Instrument layout used to obtain dielectric parameters [22]. Measures of the parallel plates capacitor probe are in millimetres.

After dielectric acquisitions, the air cell height was destructively determined averaging four measures carried out from the base of the shell to the soldering line of the shell membranes.

\subsection{Statistical analysis and classification}

Significant differences between means at different freshness categories were examined using the t-Test for independent samples; the non-parametric Mann-Whitney test was performed in the event of significance between variance means at the Levene test. Differences between means were considered significant at $\mathrm{P}<0.05$.

Linear discriminant function analysis, two group case, also called Fisher linear discriminant analysis, were performed. The original dataset was randomly divided into calibration set $(65 \%)$, validation set $(35 \%)$. The dimensional characteristics of the egg such as mass (grams), equatorial diameter (millimetres) and longitudinal diameter (millimetres), and all the measured dielectric parameters AF $(\mathrm{MHz}), \mathrm{AV}$ $(\mathrm{V}), \Delta \mathrm{F}(\mathrm{MHz}), \Delta \mathrm{V}(\mathrm{V})$, were used to classifying eggs samples into the freshness categories A "extra" and $\mathrm{A}$.

\subsection{Neural network structure}

A Multi Layer Perceptron (MLP) with Back-propagation learning algorithm was performed to set up networks in order to grade shell eggs in the freshness categories. 


\begin{tabular}{|c|c|c|c|c|c|c|c|}
\hline $\begin{array}{l}\text { Freshness } \\
\text { categories }\end{array}$ & Mass (g) & $\begin{array}{c}\text { Equatorial } \\
\text { diameter }(\mathrm{mm})\end{array}$ & $\begin{array}{c}\text { Longitudinal } \\
\text { diameter }(\mathrm{mm})\end{array}$ & $\Delta \mathrm{F}(\mathrm{MHz})$ & $\Delta \mathbf{V}(\mathbf{V})$ & $\Delta \mathrm{F}(\mathrm{MHz})$ & $\Delta \mathbf{V}(\mathbf{V})$ \\
\hline A“extra” & $63.9^{a}(3.4)$ & $44.3^{a}(0.9)$ & $56.9^{a}(2.2)$ & $116.9^{\mathrm{a}}(0.5)$ & $2.4^{a}(0.18)$ & $4.0^{a}(0.5)$ & $0.83^{\mathrm{a}}(0.17)$ \\
\hline A & $64.6^{\mathrm{a}}(4.1)$ & $44.6^{a}(1.1)$ & $57.8^{a}(1.9)$ & $116.8^{\mathrm{a}}(0.7)$ & $2.5^{\mathrm{b}}(0.19)$ & $4.2^{\mathrm{a}}(0.7)$ & $0.79^{\mathrm{a}}(0.18)$ \\
\hline
\end{tabular}

TABLE 1 - Mean values of the egg dimensional parameters and the dielectric parameters for the two freshness categories. Note: Differences between means with the same exponent letter within a column are not significant $(\mathrm{P}<0.05)$. Values in parentheses are standard deviation.

The input values were represented by the dimensional characteristics of the egg such as mass (g), equatorial diameter $(\mathrm{mm})$ and longitudinal diameter (millimetres), and the dielectric parameters $\Delta \mathrm{F}$ (MHz), $\Delta \mathrm{V}(\mathrm{V}), \Delta \mathrm{F}(\mathrm{MHz}), \Delta \mathrm{V}(\mathrm{V})$. Two nominal output variables were used to perform classification between eggs characterized by an air cell height lower than $4 \mathrm{~mm}$ (A "extra") and eggs with an air cell height between 4 and $6 \mathrm{~mm}(\mathrm{~A})$.

The software program (STATISTICA Neural Networks 4.0, Statsoft Inc.) performs classification by checking single output unit activation levels against two thresholds: the accept threshold and the reject threshold. Single output neurons are typically used for two-class problems, with a high output neuron level indicating one class and a low activation the other class. In these two-class networks, the target output is either 1.0 (indicating membership of one class) or 0.0 (representing membership of the other). Typically, values above the accept threshold are considered to be on and values below the reject threshold are considered to be off. In the present analysis the two-state conversion function was used.

The network design was approached empirically by a trial and error process: different number of hidden layer, processing elements were chosen to select the most accurate validation results. In all cases, linear scale functions $(-1,1)$ was used to assign input neuron's weights. Particularly various choices for the activation function are possible. In the developed ANN, sigmoid function $\mathrm{f}(\mathrm{x})=1 /[1+\exp (-\mathrm{x})]$ was used, where $\mathrm{x}$ is the input variable. This is a common choice as this reduces the possibility of overtraining. The maximum number of learning epochs was set to $10^{4}$.

ANN has to be tested for its generalisation ability. By adding more neurons in the hidden layer, the network becomes a very flexible function mapper, but this produces the danger of overfitting. To verify the occurrence of an overfitting problem may be used cross-validation using only the verification set and the identification of a minima in the verification error graph.

The original dataset was randomly divided into training set $(60 \%)$, verification set $(20 \%)$ and test set (20\%). The verification set was used to identify the best network on the basis of the network's performance (correct classification rate) and to stop training if over-learning occurs; the test set was performed to give an independent assessment of the network capability of grading A "extra" and A eggs.
The calculated performance indexes for each ANN were averaged on ten runs. This was made to explore the parameters space, avoiding local minima, as the training of each ANN starts from a random value of the parameters.

\section{Results and discussion}

\subsection{Statistical analysis and classification}

The observed egg dimensional parameters and the measured dielectric parameters for the two freshness categories are summarised in table 1 . Significant differences between A "extra" and A eggs, appeared only for the dielectric parameters AV (V).

From the two-group linear discriminant function analysis emerged that about only $46 \%$ of the validation data set could be correctly grading in A "extra" (table 2).

\subsection{Neural network analysis}

In table 3 was reported some representative models tested with the corresponding epoch number and performance for any data set (training, verification and test). The performance indicate the proportion of cases which are correctly classified. These values were obtained with a momentum value of 0.3 and a learning rate of 0.1 .

The structures of the best MLP neural networks tested to grading eggs in freshness categories are shown in figure 2: a) one hidden layer, and b) two hidden layers. In particular, the structure a) is characterized by 10 neurons in the hidden layers while the structure b) by 8 neurons in the first and second hidden layers.

\begin{tabular}{|ccccc|}
\hline & \multicolumn{2}{c}{ Calibration } & \multicolumn{2}{c|}{ Validation } \\
& A “extra” & A & A “extra” & A \\
\hline Cases number & 40 & 67 & 24 & 34 \\
Correct & 36 & 53 & 11 & 31 \\
Wrong & 4 & 15 & 13 & 3 \\
\hline
\end{tabular}

TABLE 2 - Results of two-group linear discriminant function analysis. 


\begin{tabular}{|ccccccc|}
\hline Input & $\begin{array}{c}\text { Hidden } \\
\text { layer (1) }\end{array}$ & $\begin{array}{c}\text { Hidden } \\
\text { layer (2) }\end{array}$ & Epochs & $\begin{array}{c}\text { Performance } \\
\text { training set }\end{array}$ & $\begin{array}{c}\text { Performance } \\
\text { verification set }\end{array}$ & $\begin{array}{c}\text { Performance } \\
\text { tes tset }\end{array}$ \\
\hline 7 & 7 & - & 100 & 0.87 & 0.87 & 0.67 \\
7 & 8 & - & 80 & 0.87 & 0.90 & 0.80 \\
7 & 8 & - & 60 & 0.82 & 0.87 & 0.63 \\
7 & 8 & 8 & 140 & 0.87 & 0.97 & 0.93 \\
7 & 8 & 8 & 180 & 0.89 & 0.97 & 0.87 \\
7 & 9 & - & 250 & 0.87 & 0.93 & 0.67 \\
7 & 10 & - & 210 & 0.90 & 0.97 & 0.90 \\
7 & 13 & - & 50 & 0.86 & 0.90 & 0.67 \\
\hline
\end{tabular}

TABLE 3 - Performance of some neural networks tested.

\begin{tabular}{|cccc|}
\hline & Training & Verification & Test \\
\hline Cases Number & 105 & 30 & 30 \\
\hline Correct & $93.4(1.9)$ & $26.7(0.9)$ & $25.8(1.3)$ \\
\hline Wrong & $11.5(1.9)$ & $3.3(0.9)$ & $4.2(1.3)$ \\
\hline
\end{tabular}

TABLE 4 - Results of training, verification and test of best MLP neural network with one hidden layer. Mean data on 10 runs with random starting parameters value. In brackets the mean square deviation is reported.

\begin{tabular}{|cccc|}
\hline & Training & Verification & Test \\
\hline Cases Number & 105 & 30 & 30 \\
Correct & $94.3(1.4)$ & $26.9(2.3)$ & $26.2(2.3)$ \\
Wrong & $10.7(1.4)$ & $3.14(2.3)$ & $3.8(2.3)$ \\
\hline
\end{tabular}

TABLE 5 - Results of training, verification and test of best MLP neural network with two hidden layers. Mean data on 10 runs with random starting parameters value. In brackets the mean square deviation is reported.
Results of training, verification and test of the selected MLP neural networks with one and two hidden layers are summarized in tables 1 and 2, respectively. The accept threshold calculated by the software was 0.3703 for both MLP neural networks.

As showed in Tables 4 and 5, the performed MLP neural networks appear to grading the eggs samples according to A"extra" and A characteristics with an acceptable performance. In particular, from test validations, about 26 eggs out of 30 of the data set are correctly graded.

Appreciable differences between the performances of the two networks does not emerge for training, verification and test.

\section{Conclusions}

The multi-layer artificial neural networks (ANN) set up in order to grading shell eggs in two categories according to the European Commission Regulation seems able to solve the non-linear problems that hard-
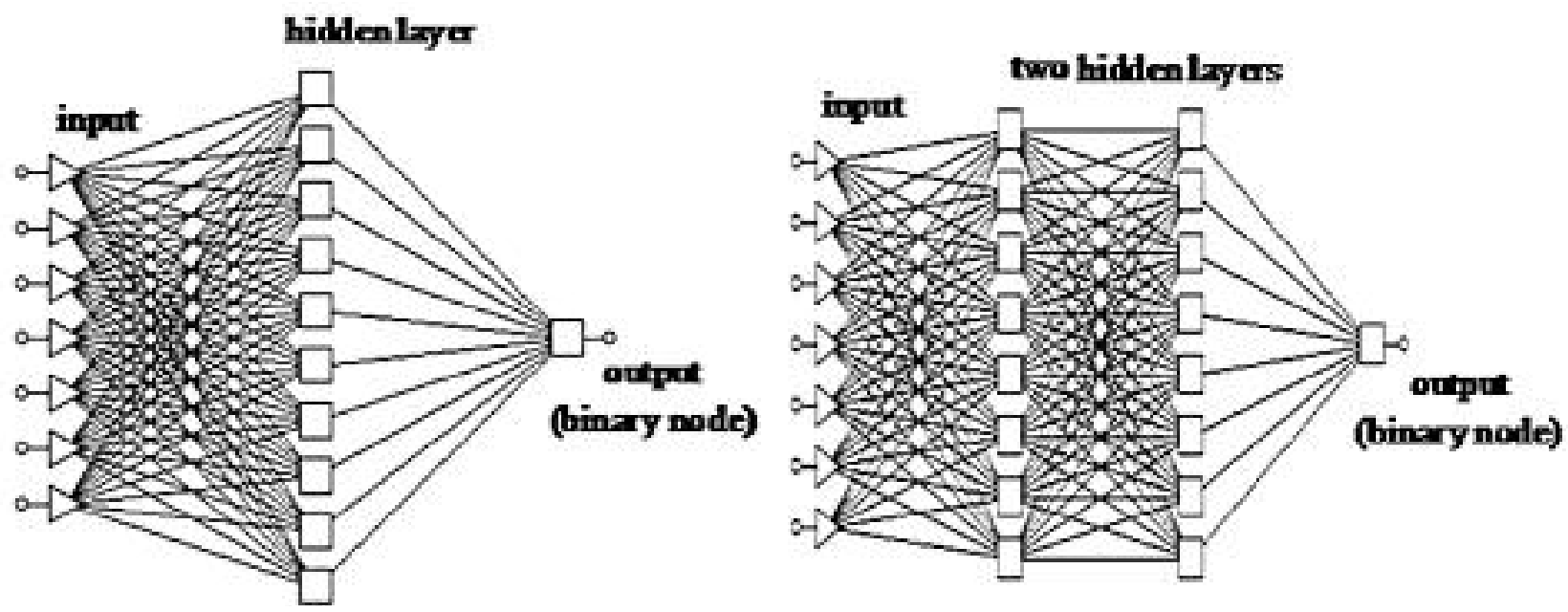

Fig. 2 - MLP neural network structures used for eggs grading in freshness categories: a) with one hidden layer (7-10-1); b) with two hidden layers $(7-8-8-1)$. 
ly can be faced by methods of classical statistical.

Using egg dimensional characteristics and dielectric parameters (obtained by means of the simple sine wave RF oscillator) as input variables, test validations show that eggs can be graded with a mean performance close to $90 \%$.

The results point out the capacity of the analysis of the dielectric properties associated with the statistical elaboration by neural networks for the egg's classification relatively to a future on-line industrial application.

\section{References}

[1] Baughman D.R \& LiU Y.A., Neural networks in bioprocessing and chemical engineering. San Diego (1995), CA: Accademic Press.

[2] Berardinelli A., Cevoli C., Fabbri A., Giunchi A., Gradari P., RAGNI L., SirRi F., "Predicting freshness of shell eggs using a technique based on the dielectric properties" Proceedings of XII European Symposium on the Quality of Eggs and Egg Products, Prague (Czech Republic) (2007), 2-5 September.

[3] Berardinelli A., Giunchi A., Guarnieri A., Pezzi F., RAGNI L., Shell egg albumen height assessment by FT-NIR spettroscopy. Transaction of the ASAE (2005) 48(4), 1426-1428.

[4] Brandon J.R., Howarth M.S., Searcy S.W., KeHTARNAVAZ N., A neural network for carrot tip classification (p. 13). ASAE. (1990), 90-7549, ASAE, St Joseph, MI.

[5] Cattaneo P., Balzaretti C., Quaglia F., Di GianCAMILlo M., Valutazione della freschezza delle uova in guscio con metodi chimici e fisici. Ingegneria Alimentare, Le Conserve Animali (1997), 13(4), 9-20.

[6] Chandraratne M.R., Kulasiri D., Samarasinghe S., Classification of lamb carcass using machine vision: Comparison of statistical and neural network analyses Journal of Food Engineering 82 (2007), 26-34.

[7] Diaz R., Faus G., Blasco M., Blasco J., Molto’ E., The application of a fast algorithm for the classification of olives by machine vision. Food Research Internationa, (2000), 33(3-4), 305-309.

[8] Diaz R., Gil L., Serrano C., Blasco M., Molto’ E., Blasco J., Comparison of three algorithms in the classification of table olives by means of computer vision. Journal of Food Engineering (2004), 61(1), 101-107.

[9] Dutta R., Hines E.L., Gardner J.W., UdRea D.D., BoILot P., Non-destructive egg freshness determination; an electronic nose based approach. Measurement Science and Technology (2003), 14, 190-198.

[10] EC, Commission Regulation No 2295/2003 of December 2003 introducing detailed rules for implementing Council regulation (EEC) No 1907/90 on certain marketing standards for eggs; Official Journal of the European Union L 340 of December.

[11] Goncalves E.C., Minim L.A., Coimbra J.S.R., MinIM V.P.R., Modeling sterilization process of canned foods using artificial neural networks. Chemical Engineering and Processing (2005), 44(12), 1269-1276.

[12] Hornik K., Stinchcombe M., White H., Multilayer feedforward networks are universal approximators. Neural Networks (1989), 2(5), 359-366.
[13] Kemps B.J., Bamelis F.R., De Ketelaere B., Mertens K., Tona K., DeCuypere E.M., DE BAERDEMAEKER J.G., Visible transmission spectroscopy for the assessment of egg freshness. Journal of the Science of food and Agriculture (2006), 86, 1399-1406.

[14] Kerdpiboon S., Kerr W.L, Devahastin S., Neural network prediction of physical property changes of dried carrot as a function of fractal dimension and moisture content. Food Research International (2006), 39, 1110-1118.

[15] McCulloch W.S., PItTs W., A logical calculus of the ideas immanent in nervous activity. Bulletin of Mathematical Biophysics (1943), 5, 115-133.

[16] MiLler W.M. OpticAl defect analysis of Florida citrus. Applied Engineering in Agriculture, ASAE (1995), 11(6), 855-860.

[17] Minsky M., PAPERT S., Perceptrons: An Introduction to Computational Geometry. The MIT Press (1969).

[18] NaKano K., KuRata K., Kaneko M., Studies on sorting systems for fruits and vegetables. Journal of the Society of Agricultural Structures (1992), 23, 81-86.

[19] NAKANo K., Application of neural networks to the color grading of apples. Computers and Electronics in Agriculture (1997), 18, 105-116.

[20] Nelson S.O., Dielectric properties of agricultural product measurements and applications. IEEE Transactions on Electrical Insulation (1991), 26, 845-869.

[21] Paliwal J., Visen N.S., JAYAS D.S., Evaluation of neural network architectures for cereal grain classification using morphological features. Journal of Agricultural Engineering Research (2001), 79(4), 361-370.

[22] Ragni L., Gradari P., Berardinelli A., Giunchi A., GUARNIERI A., Predicting quality parameter of shell eggs using a simple technique based on the dielectric properties. Biosystems Engineering (2006), 94(2), 255-262.

[23] Romanoff A.L., Romanoff A.J., The Avian Egg. New York: John Wiley \& Sons Inc. (1949).

[24] Rossi M., Pompei C., Dal Corno P., Use of new freshness indices to study the quality of eggs from the Italian market. Proceedings of VIII European Symposium on the Quality of Eggs and Egg Products, Vol. II Bologna (1999), 19-23 September

[25] Rumelhart D.E., McClelland J.L., Parallel Distributed Processing: Explorations in the Microstructure of Cognition. The MIT Press (1986).

[26] SмiтH M., Neural networks for statistical modelling. International Thomson Computer Press, London (1996).

[27] Stadelman W.J., CotTerill O.J., Egg science and technology. Food Product Press Fourth edition, NewYork (1995).

[28] STORBeCK F., DAAN B., Fish species recognition using computer vision and a neural network. Fisheries Research (2001), 51(1), 11-15.

[29] Thapon J.L., Bourgeols C.M., L'ouf et les ovoproduits. Paris: Technique et Documentation, Lavoisier (1994).

[30] Versari A., Parpinello G.P., Fabbri A., DomeniChelli S., Mesisca V., Cavicchi L., Discrimination of apricot cultivars by gas multisensor array using an artificial neural network, Biosystems Engineering (2007), 97(3), 371-378. 


\section{SUMMARY}

The increase in size of the air cell is related to the aging process of the eggs. According to the European Commission Regulation, eggs must be classified in A (air cell size higher than $4 \mathrm{~mm}$ ), and A "extra" (air cell size lower than $4 \mathrm{~mm}$ ) categories by candling inspection. This technique is unable to non-destructively assess the size of the air cell during egg grading.

The present research studies the possibility to nondestructively grading shell eggs from dielectric parameters obtained by means of a sine wave RF oscil- lator, a parallel inductance and capacitance circuit. In particular, dielectric parameters and egg dimensional characteristics were used to set up multi-layer (MLP) artificial neural networks.

Using MLP with two hidden layers, eggs can be correctly graded in A and A "extra" categories (test validation) within a mean performance close to $90 \%$.

\section{Key words:}

artificial neural networks, dielectric properties, eggs. 